\title{
Chapter 3 \\ Radiocesium Absorption by Rice in Paddy \\ Field Ecosystems
}

\author{
Keisuke Nemoto and Jun Abe
}

\begin{abstract}
Although most of the radiocesium fallout that deposited in paddy fields after the Fukushima nuclear disaster in March 2011 was expected to be bound to clay in the soil resulting in a very low soil-to-plant transfer function, a radiocesium contamination level of $>500 \mathrm{~Bq} / \mathrm{kg}$ was detected in brown rice grown in several hilly areas of Fukushima Prefecture in the autumn of the same year. The likely source of the radiocesium was fallout deposited on organic matter in the paddy fields and litter in mountain forests, from which runoff water flowed into irrigation channels that ultimately lead to the paddy fields. This problem appears to have been caused by conditions specific to lowland rice paddy fields, which are wetland ecosystems. Integrated studies of the soil, water, and plants from an ecological viewpoint are necessary to understand the mechanism of radiocesium absorption by rice before commercial rice production in the affected areas can be resumed.
\end{abstract}

Keywords Irrigation water $\bullet$ Paddy field ecosystems $\bullet$ Radiocesium $\bullet$ Rice (Oryza sativa L.)

\section{Abbreviations}

Cs Cesium

N Nitrogen

K. Nemoto $(\square) \bullet J$. Abe

Graduate School of Agricultural and Life Sciences, The University of Tokyo,

1-1-1 Yayoi, Bunkyo-ku, Tokyo 113-8657, Japan

e-mail: unemoto@mail.ecc.u-tokyo.ac.jp; junabe@agrobio.jp 


\subsection{Introduction}

The nuclear disaster in Fukushima in March 2011 released considerable amounts of various radionuclides and contaminated extensive areas of farmlands. Radiocesium comprised the majority of the radionuclides released and special attention needs to be paid to ${ }^{137} \mathrm{Cs}$ because of its long half-life.

In general, plants absorb radioactive materials: (1) directly from the surface through their aerial parts or (2) through root uptake. After the radioactive material was released into the atmosphere, it adhered to the surfaces of the aerial parts of plants where direct absorption occurred, which was the major source of contamination in plants immediately after the release of the radioactive material. The radioactive material then entered the environment and moved into the soil, where it was absorbed through the roots resulting in long-term contamination of crops. The level of root absorption is greatly affected by the behavior of the radioactive material in the soil and the soil-to-plant transfer factor depends on the specific soil type because radioactive materials such as cesium are strongly bound to the soil granules (Yamaguchi et al. 2012). Because the typical farm soil in the affected area (mainly Fukushima) was a gray lowland soil, which binds cesium strongly, the radiocesium contamination of various crops through root absorption was much lower than the provisional regulation level $(500 \mathrm{~Bq} / \mathrm{kg})$ in most cases during 2011 .

A low level of radiocesium contamination was also expected in rice (Oryza sativa L.). Half way through the investigation of radioactive contamination (pilot survey) of rice in mid-September of 2011, the radiocesium concentration in brown rice was below the detection limit at most test sites and the highest contamination level was approximately $1 / 4$ th of the provisional regulation level. However, in the subsequent investigation, the radiocesium concentration was close to or $>500 \mathrm{~Bq} / \mathrm{kg}$ in many samples of brown rice from several localities in the hilly areas of Fukushima Prefecture (e.g., Obama district in Nihommatsu City, Onami district in Fukushima City, and Oguni district in Date City), which surprised the whole of Japanese society. The radiocesium absorption level in the rice grown in these paddy fields was extraordinarily - 100 times or more than that in the flatland areas of Fukushima Prefecture such as Koriyama City. The mechanism underlying this unusual absorption was unclear, and a rapid investigation is necessary before the crop production can be resumed in the affected area. In this paper, we will summarize our most current knowledge about this problem.

\section{2 "Seasonality" in the Radiocesium Absorption Level of Rice}

The temporal pattern of radiocesium absorption by plants (i.e., the time course of absorption throughout the plant growth stages) can be estimated from the spatial distribution of the absorbed material in the plant body, provided the material has low mobility in the living plant (Tanoi et al. 2011). We used this approach to investigate the distribution of radiocesium in rice plants. 


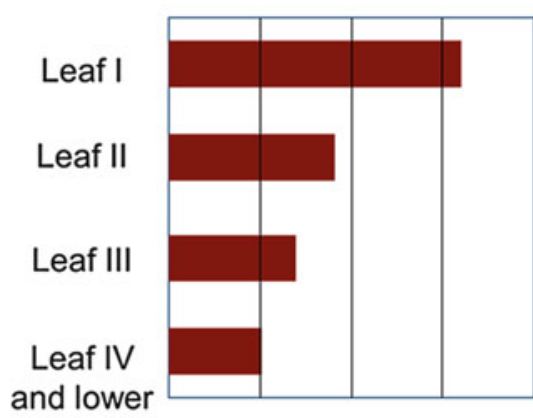

Mountain district (Obama)

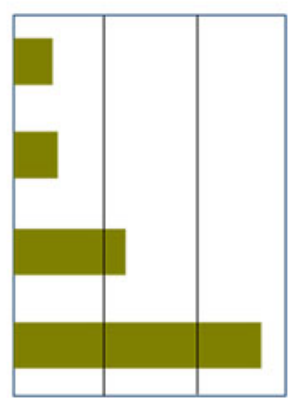

Flatland (Koriyama)

${ }^{137} \mathrm{Cs}$ concentration in leaf

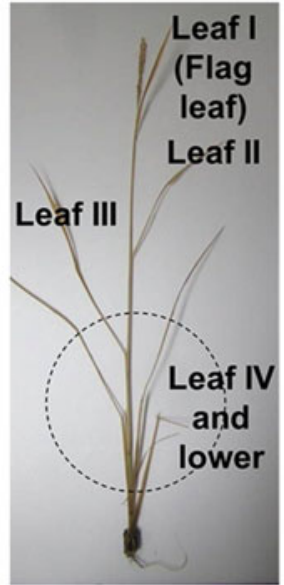

Fig. 3.1 Distribution of radiocesium in rice. The ${ }^{137} \mathrm{Cs}$ concentration was evaluated using an imaging plate method (Tanoi et al. 2013)

The radiocesium concentration in leaves decreased acropetally from the lower leaves (old leaves) to the upper leaves (new leaves) in rice plants grown in a paddy field at Fukushima Agricultural Technology Center in Koriyama City, where the radiocesium concentration of brown rice was only approximately $5 \mathrm{~Bq} / \mathrm{kg}$. In contrast, the radiocesium concentration increased acropetally in the successive leaves of rice plants grown in a paddy field in Obama, where $470 \mathrm{~Bq} / \mathrm{kg}$ radiocesium was detected in brown rice (Fig. 3.1). This distribution pattern suggests that considerable amount of radiocesium was absorbed by the rice roots in midsummer in Obama when the upper leaves were growing actively.

The most likely explanation of these findings is the promotion of organic matter decomposition under high temperatures. Organic matter decomposition is enhanced greatly in paddy fields when the air temperature exceeds $30^{\circ} \mathrm{C}$, which could have released radiocesium from radiocesium-contaminated organic matter. Various types of organic matter such as crop residues and weeds could have been sources of radiocesium in the paddy fields in Obama, Onami, and Oguni (Shiozawa 2012). Furthermore, radiocesium derived from litter deposited in mountain forests may have entered the mountain runoff and flowed into the paddy fields where it was absorbed by rice. In fact, many of the paddy fields that exceeded the provisional regulation level used mountain runoff as an irrigation source because it is very rich in nutrients such as potassium and magnesium (Fig. 3.2). Although the concentration of ionized radiocesium in the mountain runoff was rather low, the radiocesium concentration in the suspended solids (colloid) increased to several $\mathrm{Bq} / \mathrm{L}$ after rainfall (unpublished data). Thus, it is important to determine how the suspended organic material decomposes to release ionized radiocesium into the irrigation water. 
Fig. 3.2 Mountain runoff water flowing into a river that is often used for paddy field irrigation in mountain districts

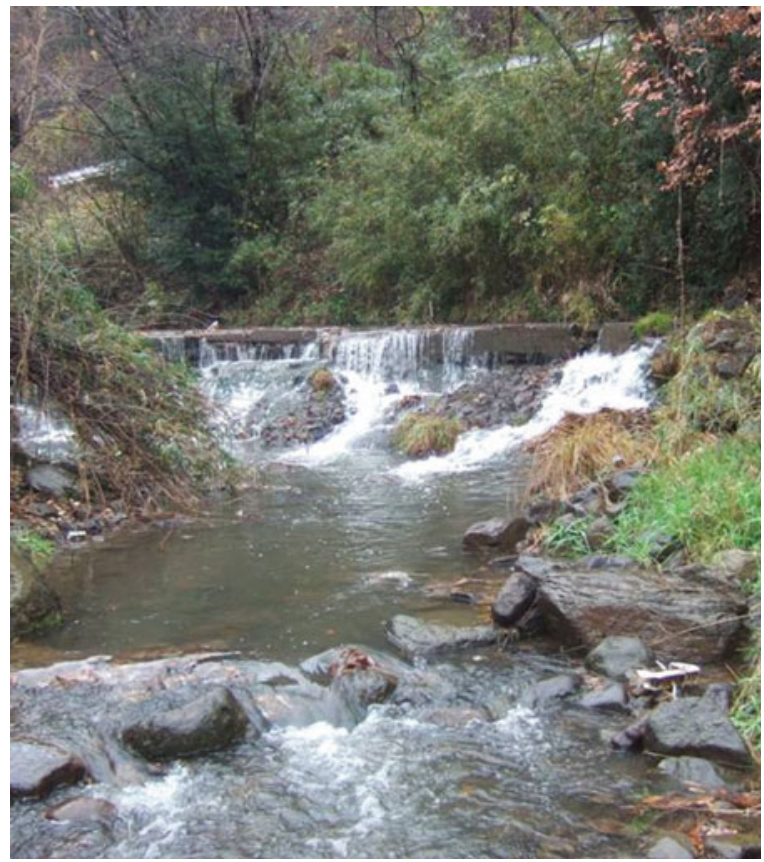

\subsection{Radiocesium Absorption Reflects the Features of the Paddy Field Ecosystem}

In paddy field ecosystems, the accumulation and decomposition of organic matter and the input of irrigation water are essential factors that determine the sustainability of production. Between the autumn and the spring, crop residue decomposition is suppressed by low temperatures and anaerobic conditions, whereas intensive organic matter decomposition occurs in summer, resulting in the release of nutrients required for plant growth in abundance. Irrigation water also provides an abundance of natural nutrients; runoff from mountain forests is particularly rich in potassium and magnesium. Our ancestors understood these ecological consequences based on the experiences of generations of farmers and they sited their paddy fields in locations with a rich forest in the upper stream catchment. There is a saying in Japanese that "Rice yield depends on the soil, wheat and barley on the manure," which suggests the sustainability of paddy ecosystems. Our hypothesis about radiocesium contamination of rice predicts that the mechanism of contamination is inextricably linked to the unique features of nutrient flow and cycling in paddy field ecosystems (Fig. 3.3).

The flooding of paddy fields may enhance radiocesium absorption in some cases. It is well known that direct cesium absorption from water is much easier compared with absorption from soil. We conducted a hydroponic culture experiment where the culture solution contained radiocesium released by the nuclear disaster at $1 \mathrm{~Bq} / \mathrm{L}$ 


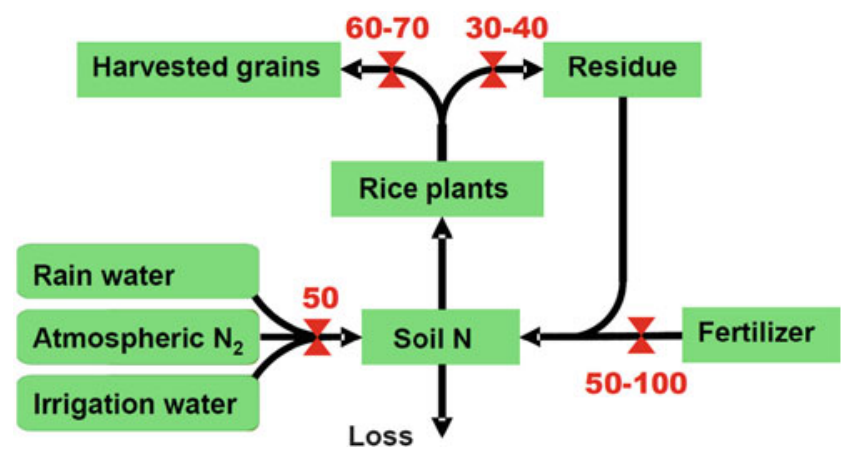

Fig. 3.3 Nutrient flow and cycling in the paddy field ecosystem. This diagram shows the nitrogen cycle in a typical paddy field in Japan. The numbers indicate the level of nitrogen input or output (kg/ha) per year

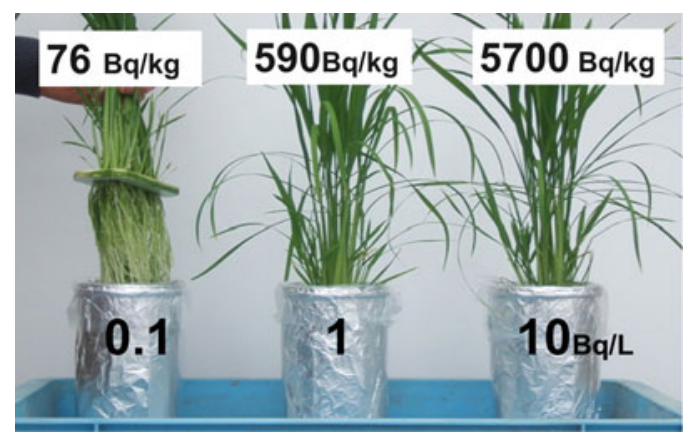

Fig. 3.4 Uptake of radiocesium by rice in hydroponic culture. Radiocesium fallout was collected from wheat leaves affected by the Fukushima nuclear disaster and the fallout was added to the hydroponic solution at three different concentrations. The concentration of radiocesium that accumulated in the rice shoots was measured using a germanium semiconductor detector after 26 days of cultivation

and rice plants accumulated radiocesium concentrations of almost $600 \mathrm{~Bq} / \mathrm{kg}$ (dry matter) in their shoots (Fig. 3.4). This absorption level was 1,000 times higher than that from soil. This unusually high absorption level was undoubtedly because of the artificial culture conditions where the whole root system was exposed to the solution medium during hydroponic culture, which is not expected to occur in actual paddy fields. Nevertheless, we estimated that absorption of radiocesium by roots directly from water may have occurred before the radiocesium bound to soil, given that the water permeability of the soil was very low in most paddy fields where the radiocesium concentration exceeded the provisional regulation level $(500 \mathrm{~Bq} / \mathrm{kg})$ (Shiozawa 2012). In these conditions, the water and/or soil in the paddy fields may have remained stagnant with radiocesium-contaminated water for some period, which may have caused root absorption. There were also reports of radiocesium contamination in wasabi (Japanese horse radish; Eutrema wasabi) from some areas, 
which is often cultured using the water runoff from mountains. This also suggests the possibility of radiocesium absorption from water by roots.

Given the remarkably high efficiency of radiocesium absorption from water by roots, particular attention should be given to radiocesium contamination of the water used for commercial hydroponic vegetable production, which is often recommended as a way of avoiding radiocesium transfer from the soil to vegetables.

The effect of the exchangeable potassium concentration in the soil is another key factor. It is widely known that a low potassium concentration in the soil enhances cesium absorption by plants. A joint research project in Onami district by the Ministry of Agriculture, Forestry, and Fisheries (MAFF) and Fukushima Prefecture reported a low concentration of exchangeable potassium in paddy fields where the radiocesium concentration was high in brown rice. This report suggested that the low exchangeable potassium concentration in the paddy soil may have reinforced the radiocesium absorption by rice roots in areas where brown rice contamination exceeded the provisional regulation level. Our pot experiment using contaminated paddy soil from Obama also showed that the radiocesium uptake by rice seedlings was reduced to approximately $1 / 10$ th after the application of potassium chloride, which indicated the effectiveness of potassium fertilizer application to contaminated paddy fields as a countermeasure for absorption of radiocesium by roots.

However, we would like to point out that the conventional rice cultivation methods used in the problem area are still quite reasonable and effective given the low input requirements of sustainable agriculture. Local farmers intensively utilized the rich mineral nutrients in runoff water to produce highly palatable rice while minimizing the use of chemical fertilizers. Thus, rice plants absorbed sufficient potassium from the paddy fields, although the potassium concentration of the soil was low. However, the nuclear disaster destroyed the well-intended efforts of farmers who wanted to produce sustainable, high quality rice in Fukushima.

\subsection{Behavior of Radiocesium in Organic Matter}

As discussed above, the problem appeared to be caused by the specific conditions in lowland rice paddy fields, which are wetland ecosystems. Many useful agricultural and plant studies were reported after Chernobyl (e.g., Ehlken and Kirchner 2002), but the experience and knowledge acquired from the areas affected by the Chernobyl disaster are not directly applicable to solving the rice production issues in Fukushima. Thus, original perspectives and approaches based on agricultural research in monsoonal Asia are required to prevent radiocesium contamination of rice, which are different from those required in upland farm areas. To understand the mechanism of radiocesium contamination of rice and solve the problem, we need to analyze the flow of radiocesium through forests, mountain streams, and paddy fields.

In the hydroponic experiment mentioned above, we extracted radiocesium from the fallout deposited on field-grown wheat leaves. Unexpectedly, we found that the fallout was relatively insoluble and only a small percentage of the radiocesium could be 


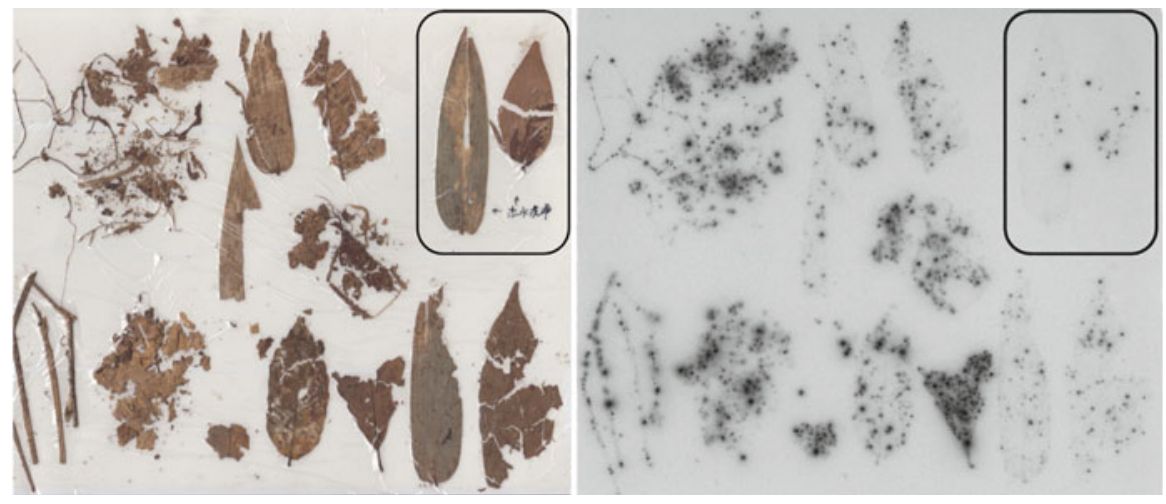

Fig. 3.5 Radioactivity in fallen leaves collected from the forest litter in Nihonmatsu-shi 8 months after the Fukushima disaster. Left, leaves; right, radioactivity detected using the imaging plate. The two leaves in the box were rinsed before measurements but they still contained scattered radiocesium

extracted by a boiling water treatment followed by nitrate leaching. We have very little knowledge about this fallout, including its chemical form and properties, but huge amounts of this relatively insoluble radioactive fallout are still bound to organic matters in paddy fields and litter in mountain forests (Fig. 3.5). Because it will take several years before the litter on the forest floor decomposes completely, the release of radiocesium from the litter to the environment will probably last for a long period. Thus, it is necessary for agricultural, soil science, plant nutrition, and forestry scientists to collaborate in the continued long-term monitoring of radiocesium in regional ecosystems.

\subsection{Can Breeding Resolve the Problem?}

We have discussed the possible mechanism of radiocesium contamination in rice from an ecological perspective; besides, breeding new rice cultivars that absorb less radiocesium is another important approach that may solve the problem. Thus, we screened rice varieties to acquire basic information relevant to future breeding efforts. Over 100 rice varieties were grown using highly contaminated soil and their radiocesium uptake capacities were measured during the vegetative stage. The radiocesium uptake during the vegetative phase was generally higher in japonica varieties compared with indica varieties. The only exception was Pokkali rice, a famous salt-tolerant indica variety, which had a higher radiocesium uptake capacity than any of the japonica varieties we tested. However, the overall range of genetic variation in the radiocesium uptake capacity was only threefold.

We also need to study the radiocesium accumulation level during the reproductive stages before we conclude the study; however, the present results suggest that the genetic variation in radiocesium uptake by rice is not sufficiently high to breed 
a new variety that could resolve the problem. Therefore, the integration of breeding with other countermeasures such as cultivation methods and civil engineering with special attention to ecophysiological and environmental aspects will be required before rice culture in the affected areas can be resumed.

\subsection{The Diagnosis of Radiocesium Absorption in Individual Paddy Fields}

It appeared that the high levels of radiocesium contamination in brown rice were caused by a complex interaction between local factors and features of the individual paddy fields. The local factors included large amounts of radioactive fallout and contaminated water that tended to accumulate in areas with mountainous geography, whereas the paddy field-specific factors included the types of organic matter and runoff water that provided a source of radiocesium, the exchangeable potassium content, the type of clay in the soil, and water percolation. Furthermore, because the decomposition rate of organic matter can differ in the leaf litter produced by various trees, the end of the radiocesium contamination risk for rice will also depend on the organic matter type.

Solving the problem of radiocesium contamination in rice demands the clarification of general factors in affected areas and the detection of radiocesium absorption in individual paddy fields. Unfortunately, detailed data were not available for individual paddy fields during 2011 because the rice harvested from individual paddy fields was gathered when the brown rice contamination level exceeded $500 \mathrm{~Bq} / \mathrm{kg}$. Thus, it is necessary to conduct further field studies to diagnose individual paddy fields. We are conducting rice cultivation field experiments in some areas of Date City this year (2012), where radiocesium contamination levels exceeding $500 \mathrm{~Bq} / \mathrm{kg}$ were detected in some brown rice samples in 2011 . We intend to diagnose individual paddy fields to support the resumption of rice production by native farmers in these areas.

Acknowledgments The studies reported in this chapter were performed as collaborative research by three groups from the Graduate School of Agricultural and Life Sciences of the University of Tokyo (Laboratory of Radioplant Physiology, Laboratory of Land Resource Science, Laboratory of Crop Ecology and Morphology) and Fukushima Agricultural Technology Centre.

Open Access This article is distributed under the terms of the Creative Commons Attribution Noncommercial License which permits any noncommercial use, distribution, and reproduction in any medium, provided the original author(s) and source are credited.

\section{References}

Ehlken S, Kirchner G (2002) Environmental processes affecting plant root uptake of radioactive trace elements and variability of transfer factor data: a review. J Environ Radioact 58:97-112

Shiozawa S (2012) Mechanisms of soil-to-plant transfer of radiocesium in rice grown in paddy fields. In: Abstract for 2nd progress report meeting of studies on the effects of radioactivity on 
agricultural, livestock and fishery products (in Japanese, Title translated by present authors) http://www.a.u-tokyo.ac.jp/rpjt/event/20120218-4.pdf. Retrieved on 20 Nov 2012

Tanoi K, Hashimoto K, Sakurai K, Nihei N, Ono Y, Nakanishi TM (2011) An imaging of radioactivity and determination of Cs-134 and Cs-137 in wheat tissue grown in Fukushima. Radioisotopes 60:317-322 (in Japanese with English abstract)

Tanoi K, Kobayashi NI, Ono Y, Fujimura S, Nakanishi TM, Nemoto K (2013) Radiocaesium distribution in rice plants grown in the contaminated soil in Fukushima Prefecture in 2011. Radioisotopes 62:25-29 (in Japanese with English abstract)

Yamaguchi N, Takata Y, Hayashi K, Ishikawa S, Kuramata M, Eguchi S, Yoshikawa S, Sakaguchi A, Asada K, Wagai R, Makino T, Akahane I, Hiradate S (2012) Behavior of radiocaesium in soil-plant systems and its controlling factor: a review. Bull Natl Inst Agro-Environ Sci 31:75-129 (in Japanese with English summary) 